\title{
A national survey of ambient air pollution health literacy among adult residents of Taiwan
}

Wen-Hsuan Hou ${ }^{1,2,3}$, Yi-Chin Huang ${ }^{4}$, Chien-Yeh Lü ${ }^{4}$ I-Chen Chen ${ }^{4,5}$, Pei-Chen Lee ${ }^{6}$, Ming-Yeng Lin${ }^{7}$, Yu-Chen Wang ${ }^{8}$, Lilis Sulistyorini ${ }^{9}$ and Chung-Yi Li $i^{4,9,10,11^{*}}$

\begin{abstract}
Objective: To investigate the level of and covariates associated with ambient air pollution health literacy (AAPHL) among adult residents of Taiwan.

Methods: With a cross-sectional study design, we conducted telephone interviews using a Chinese version AAPHL scale, which consisted of 24 items assessing 12 subdomains of AAPHL formed by 4 information processing competence matrices (i.e., access, understand, appraise, and apply) and 3 health contexts (i.e., healthcare, disease prevention, and health promotion). The AAPHL was with the lowest and highest score at 1 to 4 , respectively. Between September and November 2020, a sample of 1017 and 280 adults was successfully interviewed via home phones and mobile phones, respectively. We employed multiple linear regression models to identify covariates significantly associated with overall and 4 matric-specific AAPHL scores.

Results: The mean and standard deviation ( \pm SD) of overall AAPHL score was considered as moderate at $2.90( \pm 0.56)$, with the highest and lowest metric-specific score for "apply" (3.07 \pm 0.59$)$ and "appraise" ( $2.75 \pm 0.66)$. Lower education was significantly associated with a lower overall score; and living with children $<12$ years and single were both significantly associated with higher overall scores. We also noted a significant geographic variation in overall score in which people living in the east/remote islands had highest scores.

Conclusions: People in Taiwan had only moderate level of AAPHL; and covariates including education, living arrangement, marital status, and area of living were significantly associated with AAPHL. These covariates should be considered in future educational interventions aiming to improve the AAPHL in the community.
\end{abstract}

Keywords: Ambient air pollution, environmental health literacy, Cross-sectional studies, Community health, Linear regression model

\footnotetext{
* Correspondence: cyli99@mail.ncku.edu.tw

${ }^{4}$ Department of Public Health, College of Medicine, National Cheng Kung University, \#1, University Rd, Tainan, Taiwan 701

${ }^{9}$ Department of Environmental Health, Faculty of Public Health, University of Airlangga, Surabaya, Indonesia

Full list of author information is available at the end of the article
}

(c) The Author(s). 2021 Open Access This article is licensed under a Creative Commons Attribution 4.0 International License, which permits use, sharing, adaptation, distribution and reproduction in any medium or format, as long as you give appropriate credit to the original author(s) and the source, provide a link to the Creative Commons licence, and indicate if changes were made. The images or other third party material in this article are included in the article's Creative Commons licence, unless indicated otherwise in a credit line to the material. If material is not included in the article's Creative Commons licence and your intended use is not permitted by statutory regulation or exceeds the permitted use, you will need to obtain permission directly from the copyright holder. To view a copy of this licence, visit http://creativecommons.org/licenses/by/4.0/ The Creative Commons Public Domain Dedication waiver (http://creativecommons.org/publicdomain/zero/1.0/) applies to the data made available in this article, unless otherwise stated in a credit line to the data. 


\section{Introduction}

Ambient air pollution is a major environmental health problem affecting everyone in low-, middle-, and highincome countries; and representing a considerable threat to health worldwide [1]. According to the definition form WHO, ambient air pollution is a broader term used to describe air pollution in outdoor environments, while urban outdoor air pollution is a more specific term referring to the ambient air pollution experienced by populations living in urban areas, typically in or around cities [1, 2]. According to the 2015 Global Burden of Disease Study [3], exposure to ambient fine particulate matter $\mathrm{PM}_{2.5}$ is the fifth leading cause of death worldwide, accounting for 4.2 million deaths and 103.1 million disability-adjusted life-years in 2015 globally. Epidemiological studies reported links between air pollution and certain diseases of public health importance such as cardiovascular diseases, cancers, and respiratory diseases [4]. Recent studies also revealed potential influence of air pollution on psychiatric disorders $[5,6]$. Taiwan is no exception [7]. Estimated in 2014, $\mathrm{PM}_{2.5}$ accounted for 6,282 deaths from ischemic heart disease, stroke, lung cancer, and chronic obstructive pulmonary disease, representing a population attributable mortality fraction of $18.6 \%$ associated with the four disease causes [7].

Ambient air pollution is a function of complex systems, and solutions to the problem also require multilevel intervention [8]; and education of people involved in the air pollution control strategies, including scientists, negotiators, decision makers and the public, to raise the environmental awareness is essential for reducing the air pollution [9]. Previous studies have demonstrated that environmental health education interventions at formal education or in the community could significantly have knowledge gains related to environmental health, individual behavior changes, and collective action for community change [10, 11]. Effective educational interventions were found to increase prevalence and effects of so-called avoidance behaviors in lowering the adverse effects of air pollution on health [12]. Such activities include purchasing preventive pharmaceuticals and reducing time spent in polluted environments [13].

The knowledge of environmental health and the behavior of environmental protection, which is so called environmental health literacy (EHL), with a root of both health literacy [14] and risk communication [10, 11], is an emerging area of study that incorporates content and strategies from environmental, health, and social sciences to promote understanding of the ways environmental contaminants affect health [15], which can be used as a tool for evaluating the effectiveness of environmental education. The earlier conceptual model of EHL was adapted from Bloom (1956), representing the stepwise progression of six distinct educational stages (i.e, create, evaluate, analyze, apply, understand, and recognize) to approach the development of targeted interventions for different levels of EHL [16]. The EHL on ambient air pollution can be enhanced by empowering individuals and communities to use appropriate communication for controlling air pollution exposures. However, to the best of our knowledge, previous air pollution assessments were focused on the air pollutants concentration or air quality monitoring $[17,18]$, and our study is the first one that assessed the level of ambient air pollution health literacy (AAPHL) in the general population. In fact, there is still a lack of easy and selfadministrated checklist items like the one that we used in the current study for assessing the level of knowledge, competence, and motivation in dealing with ambient air pollution and human health. AAPHL which is defined as individual's competencies to access, understand, appraise, and apply the ambient air pollution health information to make judgments and decisions concerning healthcare, disease prevention, and health promotion contexts to maintain or improve their quality of life and to protect the environment in urban and non-urban community [19]. The questionnaire was developed based on three rounds of consensus meetings including 5 experts of public health, environmental science, medical physicians, and air pollutant researchers in order to reflect the synergized subjective opinions of AAPH L. The content of the AAPHL scale included questions related to both urban and non-urban ambient air pollutant categories, air quality detection, pollutant sources, control strategies, law regulations, application of health-related information according to the above health literacy subdomains. Therefore, we developed the AAPHL questionnaire on the basis of an existing conceptual framework of health literacy proposed by the European Health Literacy Consortium, which composed of 12 subdomains of health literacy formed by 4 information processing competencies of individuals (ie, accessing, understanding, appraising, and applying) and 3 health contexts (ie, healthcare, disease prevention, and health promotion) [19]. Despite that, only very few studies have been conducted to address the issue of EHL on ambient air pollution and health threats [20, 21], and no survey data on ambient air pollution health literacy available at a populationbased level. We therefore conducted this national population-based survey on level of AAPHL in adult residents of Taiwan.

\section{Methods}

The study was ethnically approved by the National Chung Kung University Governance Framework for Human Research Ethics (No. 109-385). 


\section{Study design and participants}

This was a population-based cross-sectional study design. The target population was all Taiwanese residents aged 20 years and older. There are 22 cities/counties in Taiwan. By the end of 2019, a total of 19,338,629 adult ( $>=20$ years) residents including 9,486,379 men and 9,852,250 women were registered in the Household Registration [22]. These adults were inhabitants of $6,956,341$ households all over the country. Seven covariates which are potential predictors (i.e., gender, age, education, and occupation as the personal determinants; living arrangement and marital status for situational determinants; living area as a socio-environmental determinants) for AAPHL scores were tested in this study on the basis of the integrated model of health literacy proposed by the European Health Literacy Survey Consortium [19].

The sample size required for this survey was calculated based on the multiple linear regression that identified factors significantly associated with AAPHL. Given that there were 7 potential covariates assessed for their associations with AAPHL, a sample size of 107 may achieve $90 \%$ power to detect a partial $\rho^{2}$ of at least 0 (null hypothesis) attributed to 7 independent variable(s) when the significance level (alpha) is 0.050 and the actual value of $\rho^{2}$ is 0.1 (alternative hypothesis). The corresponding sample size for a smaller actual value of $\rho^{2}=$ 0.05 and $\rho^{2}=0.01$ was 212 and 1,017, respectively (NCSS, LLC, Utah USA). Because the 7 covariates included in the models were potentially associated with health literacy (see the Covariate section below), we believe that they may have at least a partial $\rho^{2}$ of 0.01 , and as such a minimum of 1017 participants is needed for this study. The main purpose of cell phone survey was to increase the representativeness of those who do not have home phones. The number of 280 cell phone interviews was arbitrarily determined based on the availability of time and funding.

\section{Instrument and measurements of AAPHL}

The Chinese version AAPHL scale was developed on the basis of The European Health Literacy Survey Questionnaire (HLS-EU-Q) [23]. The AAPHL was designed to be an integrated model of EHL, which comprised 24 items assessing 12 subdomains of EHL formed by 4 information processing competencies of individuals (i.e., accessing/obtaining information, understanding information, appraising/processing information, and applying/using information) and 3 health contexts (i.e., healthcare, disease prevention, and health promotion) to maintain or improve their quality of life and protect the environment in the community. The questionnaire was developed based on three rounds of consensus meetings including 5 experts of public health, environmental science, medical physicians, and air pollutant researchers in order to reflect the synergized subjective opinions of AAPHL. The content of the AAPHL scale included questions related to both urban and non-urban outdoor air pollutant categories, air quality detection, pollutant sources, control strategies, law regulations, application of health-related information according to the above health literacy subdomains. The HLS-EU-Q is highly recommended because it is founded on a testable conceptual framework, captures multiple conceptual domains of health literacy, and covers a diverse range of health contexts $[24,25]$. Contents of the Chinese version AAPHL scale were displayed in Supplementary Table 1.

Two environmental epidemiologists and one environmental health scientist who have expertise on air pollution and human health were asked to perform content validity that assesses whether our AAPHL scale is representative of all aspects of the construct, namely the three health contexts: (1) healthcare; (2) disease prevention; (3) health promotion, and each context explored four health information processing competences: accessing/ obtaining information; understanding information; processing/appraising information and applying/using information. The 4-point Liker's scale was used to indicate the level of appropriateness for 3 categories in "relevance", "importance", and "unambiguity", respectively of the AAPHL scale. The mean score for "relevance", "importance", and "unambiguity" of the scale was 3.90, 3.97, and 3.91, respectively; and the corresponding figures of Content Validity Index (CVI) were 0.97, 0.99, and 0.94, which were calculated from the method proposed by Aiken [26].

Apart from the content validity, we also examined the construct validity to evaluate whether the Chinese version AAPHL scale really represents the concept (i.e., construct) we are interested in measuring. Information of construct validity is central to establishing the overall validity of a method [27]. Based on the data of our study, we performed confirmatory factor analysis (CFA) to assess the construct validity. We performed a first-order CFA to verify the 12-subdomain factor structure of the Chinese version AAPHL scale. The first-order model was considered valid if the CFA demonstrated acceptable fit between the overall model and data on the basis of the following absolute and relative fit indices: (1) the $x^{2}$ test: it indicates the difference between observed and expected covariance matrices. Values closer to zero indicate a better fit; (2) the root mean squared error of approximation (RMSEA) of 0.08 or less [28]; (3) the standardized root mean square residual (SRMR) of 0.08 or less [29]; (4) the adjusted goodness of fit index (AGFI) of 0.80 or over [30]; and (5) both the normed fit index (NFI) and non-normed fit index (NNFI) of 0.90 or greater [29]. 
Although the $\chi^{2}$ test indicates a significant difference $(p<0.001)$ between observed and expected covariance matrices in our sample, the other fit indices tended to support the factorial validity of the 12-subdomain factor structure of the Chinese version AAPHL: RMSEA = $0.067 ; \quad \mathrm{SRMR}=0.039 ; \quad \mathrm{AGFI}=0.864 ;$ and $\mathrm{NFI} / \mathrm{NNFI}=$ $0.9138 / 0.9021$. It was thus recommended that the 12 subdomain scores be summed up to represent overall AAPHL. In addition, the factor loading for the 24 items of AAPHL ranged from 0.609 to 0.881 , also suggesting an acceptable level [31].

The reliability of Chinese version AAPHL scale was determined by two internal consistence indicators. Based on our study sample, the Cronbach's alpha was calculated at 0.934 . Moreover, the composite reliability (i.e., construct reliability), a measure of internal consistency in scale items, much like Cronbach's alpha [32] and can be thought of as being equal to the total amount of true score variance relative to the total scale score variance [33] showed that the composite reliability coefficient for the "access", "understand", "appraise", and "apply" matrices was $0.852,0.839,0.845$, and 0.798 , respectively, which were all greater than an acceptable reliability level of 0.60 [32].

The possible responses and their scores for the AAPH $\mathrm{L}$ scale were as follows: very difficult $=1$, fairly difficult $=$ 2 , fairly easy $=3$, very easy $=4$, and a " 5 " was indicated when participants did not answer or did not have a definite answer, coded as a missing value. The overall AAPHL score was calculated as the mean of all items applicable, scored from 1 to 4 . Higher scores indicate better AAPHL. In addition to overall AAPHL score, we also calculated matric-specific score to indicate the information processing competencies of individuals, namely accessing, understanding, appraising, and applying matrices. Contents of the 24-item Chinese version AAPHL scale were displayed in Supplementary Table 1.

\section{Covariates}

We collected the following covariates also via telephone interview to assess their associations with AAPHL level. The covariates included gender, age (20-34, 35-44, 45$54,55-64$, and $>=65$ years), education (Junior high school and lower, high school, college, and graduate studies), current occupation, living arrangement (living alone, living with children $<12$ years, living with older $[>=12$ years $]$ students, or living with elderly [ $>=65$ years] people), marital status (single, married, others), and geographic area of living (north, central, south, and east/remote islands).

The currently held job was classified into one of 10 occupational categories: legislators, government administrators, business executives, and managers; professionals; technicians and associate professionals; clerks; service workers and shop and market sales workers; technology professionals; construction workers, agricultural, animal husbandry, forestry, and fishing workers; transportation and communication workers; teachers, athletes, and art performers; healthcare and social workers; legislators, government administrators, business executives and managers; and others (including housekeeper, retirees, and students). The occupational classification was based on the Standard Occupational Classification System (SOCS) of Taiwan for which interrater reliability has been shown to be good [34, 35].

Studies have shown that a number of factors may influence an individual's health literacy, including living in poverty, education, race/ethnicity, age, and disability [36, 37]. In addition to socioeconomic status and co-morbidity, a recent study by Cho [38] indicated an association between work environment and level of health literacy. Because the above-mentioned covariates were reported to be associated with heath literacy, rather than with EHL or specifically with AAPHL, we examined in this study whether these sociodemographic and work characteristics also influence the AAPHL level.

\section{Data collection}

The sampling method used in this study comprises two steps:. First, based on a predetermined total number of 1017 participants to be collected, we used the probability proportional to size (PPS) technique to determine the number of home phone to be called for each city/county according to the city/county specific population size $[39,40]$. The PPS resulted in the number of call to be made for each city/county ranging from 37 to 385 . Second, once the sample size was determined for each city/county we further employed a quota sampling by setting the age-specific sample size needed for each of the 7 age-specific populations (i.e., 20-29, 30-39, ... $. .80+)$ bases on the underlying age distributions of that particular city/county. The area codes and the first four digits of home phone numbers are unique for households in each city/county. The phone interviews continued until the predetermined sample size in each specific age group of specific city/county is met.

Considering an increasing number of residents in Taiwan only subscribed to mobile phones and some residents are usually not available during the period of making the home phone call, we additionally selected a supplemental sample via mobile phone. The mobile phone number is not city/county specific; therefore, the sample was selected from all mobile phone numbers of the entire country.

We employed the Computer-Assisted-Telephone Interview (CATI) to perform the interview. To achieve 
the predetermined age-specific sample size of sample for each city/county, we continuously performed the random digital dialing (RDD) procedure until the predetermined age-specific sample size was achieved. For each home phone called, only one eligible person best available in that household was invited. The CATI procedure reached a total of 4084 eligible adults via home phones, and 1017 adults successfully completed the home phone interviews, with a response rate of $24.90 \%$. Reasons for unsuccessful home phone interviews were mainly due to the interviewees felt that the interview consumed more time than he/she expected and decided not to continue (19.9\%), or the interviewees declined to be interviewed before the interview began $(80.1 \%)$. The response rate (280/835 or $33.53 \%)$ was somewhat higher for the mobile phone interview as compared to the home phone.

The interview took around $15-20 \mathrm{~min}$. The CATI was performed between September and November 2020 by five interviewers standardized to conduct telephone interviews. All phone calls were made between 5:00 PM and 10:00 PM to maximize the chance of reaching eligible subjects and to increase the likelihood of acceptance to be interviewed. Once the phone call reached a home phone/ mobile phone, the people who answered the call were asked to determine his/her age eligibility. If the person who answered the call was eligible, he/she was invited. If not eligible or declined the invitation, any other eligible subject next him/her and available was invited.

Table 1 shows that the mobile phone interviewees tended to be female dominance, younger, more educated, living alone, single, and living in the north. Despite significant differences in socio-demographic characteristics between home phone and mobile phone interviewees, there were only slight differences in overall AAPHL and matric-specific scores, we therefore combined the home phone and mobile phone samples in the subsequent analyses to increase the representativeness of our study sample (Supplementary Table 2).

\section{Statistical analysis}

We first presented characteristics of the study participants with numbers and percentages. The AAPHL score was presented with mean and standard deviation (SD), and comparison of the differences among the 4 matricspecific AAPHL scores was made with repeated measurement analysis of variance, which considers the intercorrelation of the matric-specific scores made by the same interviewee. Multiple linear regression analysis was performed to investigate the covariates significantly associated with overall and matric-specific AAPHL score separately. We checked the assumptions of linearity, normality, and homoscedasticity for linear regression model by examining the residual plots, and found no violation of the above assumptions.
All statistical analyses were performed using SAS statistical software (SAS System for Windows, Version 9.4, SAS Institute Inc., Cary, NC, USA). Results with twosided $P$ values less than .05 were considered statistically significant.

\section{Results}

Figure 1 shows the mean and SD of overall and 4 matricspecific AAPHL scores. Supplementary Table 2 further shows distributions of overall and metric-specific scores of AAPHL according to phone type. The mean and SD of overall AAPHL score was considered as moderate at 2.90 (0.56), with significant variation in metric-specific AAPHL. The highest and lowest metric-specific mean \pm SD score was noted for "apply" (3.07 \pm 0.59$)$ and "appraise" $(2.75 \pm$ 0.66), respectively. Each metric-specific AAPHL score showed a high correlation with overall AAPHL score, with a Spearman's correlation coefficient ranging from 0.83 ("apply" and overall) to 0.90 ("understand" and overall). However, the inter-correlation between the 4 metricspecific AAPHL scores was only moderate at 0.61 ("access" and "apply") to 0.74 ("access" and "understand") (Table 2).

Table 3 shows the results of multiple linear regression analysis. Covariates significantly associated with overall AAPHL score included education, living arrangement, marital status, and area of living. Compared to those with college education, the participants with education levels of high school (adjusted $\beta=-0.09$ ) and junior high school and lower (adjusted $\beta=-0.15$ ) had significantly lower overall scores. The participants living with children $<12$ years (adjusted $\beta=0.15$, with reference to those living alone) and those who were single (adjusted $\beta=0.10$, with reference to those married) had significantly higher AAPHL scores. Compared to living in the north, living in central (adjusted $\beta=0.09$ ) and east $/ \mathrm{re-}$ mote islands (adjusted $\beta=0.25$ ) were both associated with significantly higher overall AAPHL scores.

Supplementary Tables 3 to 6 showed the covariates in association with the 4 metric-specific AAPHL scores individually. Lower education was significantly associated with lower scores of all matrices except "appraise" metric. In addition, adults living with children $<12$ years had significantly higher scores in both "appraisal" and "apply" metrices; and single was significantly associated with higher scores of all matrices except "appraisal". A significant geographic variation in AAPHL score was observed for all matrices, with participants from east/remote islands had consistently higher scores. Some occupations were found to be sporadically associated with certain metric-specific AAPHL scores.

\section{Discussion}

To the best of our knowledge, this is the first study developing the measurement tool of EHL in ambient air 
Table 1 Characteristics of study participants

\begin{tabular}{|c|c|c|c|c|c|}
\hline \multirow[t]{3}{*}{ Characteristics } & \multicolumn{4}{|c|}{ Source of information } & \multirow{3}{*}{$p$ value } \\
\hline & \multicolumn{2}{|c|}{$\begin{array}{l}\text { Home phones } \\
(n=1017)\end{array}$} & \multicolumn{2}{|c|}{$\begin{array}{l}\text { Mobile phones } \\
(n=280)\end{array}$} & \\
\hline & $n$ & $\%$ & $n$ & $\%$ & \\
\hline Gender & & & & & 0.004 \\
\hline Men & 473 & 46.5 & 103 & 36.8 & \\
\hline Women & 544 & 53.5 & 177 & 63.2 & \\
\hline Age (years) & & & & & $<0.001$ \\
\hline $20-34$ & 228 & 22.4 & 79 & 28.2 & \\
\hline $35-44$ & 180 & 17.7 & 65 & 23.2 & \\
\hline $45-54$ & 222 & 21.8 & 74 & 26.4 & \\
\hline $55-64$ & 257 & 25.3 & 53 & 18.9 & \\
\hline$>=65$ & 130 & 12.8 & 9 & 3.2 & \\
\hline Education & & & & & $<0.001$ \\
\hline Junior high school and lower & 118 & 11.6 & 7 & 2.5 & \\
\hline High school & 306 & 30.1 & 67 & 23.9 & \\
\hline College & 516 & 50.7 & 181 & 64.6 & \\
\hline Graduate studies & 77 & 7.6 & 25 & 8.9 & \\
\hline Occupation & & & & & $<0.001$ \\
\hline Clerks & 52 & 5.2 & 30 & 10.9 & \\
\hline Service workers and shop and market sales workers & 214 & 21.1 & 50 & 18.1 & \\
\hline Technology professionals & 53 & 5.3 & 18 & 6.6 & \\
\hline Construction workers & 51 & 5.1 & 14 & 5.1 & \\
\hline Agriculture, animal husbandry, forestry, and fishing workers & 38 & 3.8 & 15 & 5.5 & \\
\hline Transportation and communication workers & 59 & 5.9 & 30 & 10.9 & \\
\hline Teachers, athletes, and art performers & 103 & 10.1 & 43 & 15.6 & \\
\hline Healthcare and social workers & 27 & 2.7 & 12 & 4.4 & \\
\hline $\begin{array}{l}\text { Legislators, government administrators, business executives } \\
\text { and managers }\end{array}$ & 37 & 3.7 & 14 & 5.1 & \\
\hline Others (including housekeeper, retirees, and students) & 374 & 37.1 & 49 & 17.8 & \\
\hline Living arrangement & & & & & $<0.001$ \\
\hline Living alone & 93 & 9.1 & 54 & 19.3 & \\
\hline Living with someone & 924 & 90.9 & 226 & 80.7 & \\
\hline Children $<12$ years & 225 & 22.1 & 44 & 15.7 & \\
\hline Someone who is a student and aged $>=12$ years & 407 & 40.0 & 102 & 36.4 & \\
\hline Elderly people aged $>=65$ & 420 & 41.3 & 90 & 32.1 & \\
\hline Marital status & & & & & 0.006 \\
\hline Single & 268 & 26.4 & 93 & 33.2 & \\
\hline Married & 698 & 68.6 & 145 & 51.8 & \\
\hline Others & 51 & 5.0 & 42 & 15.0 & \\
\hline Area of living & & & & & $<0.001$ \\
\hline North & 457 & 44.9 & 179 & 63.9 & \\
\hline Central & 240 & 23.6 & 45 & 16.1 & \\
\hline South & 257 & 25.3 & 46 & 16.4 & \\
\hline East and remote islands & 63 & 6.2 & 10 & 3.6 & \\
\hline
\end{tabular}




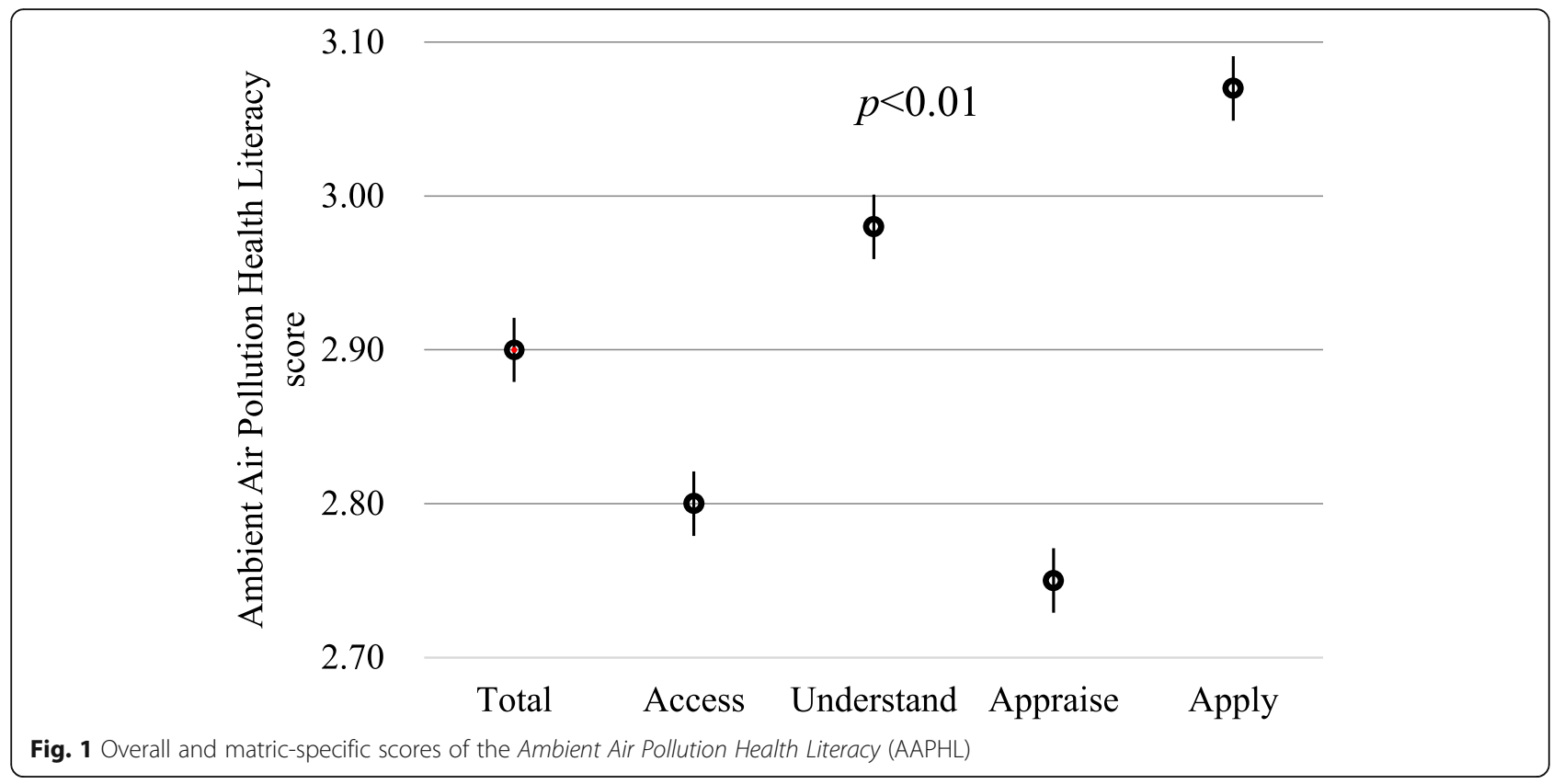

pollution, exploring the level of AAPHL nationally, and identifying covariates significantly associated with AAPH $\mathrm{L}$ score. For the AAPHL assessment, we employed the conceptual framework proposed by European Health Literacy Consortium. The comprehensive questionnaire of HLS-EU-Q47 not only assesses the concept of HL in terms of 3 health contexts (health care, disease prevention, and health promotion) and four competencies regarding health information ("access", "understanding", "appraisal", and "apply"), but also encompasses the antecedents and consequences of HL [19]. People with chronic diseases (particularly cardiorespiratory illnesses) [41, 42], little social support, and poor access to medical services are most at risk from air pollution [43]. Therefore, exploring the level of ambient air pollution healthrelated skills and identifying key covariates associated with these skills may help guide policies to improve the understanding of the link between air pollution exposures and health.

EHL is a natural outgrowth concept incorporating health literacy, public health, environmental health

Table 2 Inter-correlation among total and matric-specific scores of ambient air pollution health literacy

\begin{tabular}{llllll}
\hline Matrices & Access & Understand & Appraise & Apply & Total \\
\hline Access & $1.00^{\mathrm{a}}$ & 0.74 & 0.63 & 0.61 & 0.87 \\
Understand & & 1.00 & 0.70 & 0.68 & 0.90 \\
Appraise & & & 1.00 & 0.62 & 0.85 \\
Apply & & & & 1.00 & 0.83 \\
Total & & & & & 1.00 \\
\hline
\end{tabular}

${ }^{\mathrm{a}}$ Indicated by Spearman correlation coefficient science, and environmental literacy to develop the wide range of skills and competencies linking between environmental exposures and health [10]. Therefore, it is a must to assess the ability of population to seek out, comprehend, evaluate, and use the health information regarding to air pollution, as well as to make informed choices, reduce health risks, improve quality of life and protect the environment [11]. Both overall and matricspecific AAPHL scores in our survey revealed a sufficient (2.7-3.1 out of 4) level of health literacy which is similar as our previous study [44]. Our study showed the self-reported difficulty of AAPHL competency from the easiest to the most difficult is "apply", "understand", "access", and "appraisal". This finding is similar to the result from the previous survey conducted in eight Europeans countries proposing that tasks relating to "appreciation" or "accessing" of information are perceived as more difficult than "understanding" or "applying" information [45]. In addition, our study revealed that all four information processing competence measures have high correlation with the overall score of AAPHL. Among the four competences of "access", "understand", "appraise", and "apply" the ambient air pollution health information, the matric of "understand" correlates most to the total AAPHL while the matric of "apply" correlates least with the other three competence matrices. This implied that our current self-reported AAPHL questionnaire measures more air pollution health literacy related domains of knowledge level than skill or behavior concepts. This barrier in measuring health literacy had been noticed by a Canadian study which emphasized the "two-sided" nature of health literacy, both the knowledge and skill that 
Table 3 Multiple linear regression models of ambient air pollution health literacy score in relation to socio-demographic characteristics $(n=1297)$

\begin{tabular}{|c|c|c|c|}
\hline Characteristics & Mean \pm SD & Adjusted $\beta$ & $p$-value \\
\hline \multicolumn{4}{|l|}{ Gender } \\
\hline Men & $2.89 \pm 0.59$ & Ref. & Ref. \\
\hline Women & $2.91 \pm 0.53$ & 0.02 & 0.46 \\
\hline \multicolumn{4}{|l|}{ Age (years) } \\
\hline $20-34$ & $2.96 \pm 0.57$ & Ref. & Ref. \\
\hline $35-44$ & $2.89 \pm 0.57$ & -0.004 & 0.94 \\
\hline $45-54$ & $2.88 \pm 0.53$ & 0.01 & 0.86 \\
\hline $55-64$ & $2.91 \pm 0.56$ & 0.06 & 0.25 \\
\hline$>=65$ & $2.87 \pm 0.54$ & 0.02 & 0.81 \\
\hline \multicolumn{4}{|l|}{ Education } \\
\hline Junior high school and lower & $2.81 \pm 0.56$ & -0.15 & 0.01 \\
\hline High school & $2.85 \pm 0.58$ & -0.09 & 0.02 \\
\hline College & $2.93 \pm 0.54$ & Ref. & Ref. \\
\hline Graduate studies & $3.02 \pm 0.52$ & 0.08 & 0.20 \\
\hline \multicolumn{4}{|l|}{ Occupation } \\
\hline Clerks & $2.85 \pm 0.53$ & -0.05 & 0.46 \\
\hline Service workers and shop and market sales workers & $2.86 \pm 0.60$ & Ref. & Ref. \\
\hline Technology professionals & $3.01 \pm 0.53$ & 0.11 & 0.14 \\
\hline Construction workers & $2.87 \pm 0.71$ & -0.002 & 0.98 \\
\hline Agriculture, animal husbandry, forestry, and fishing workers & $2.93 \pm 0.42$ & 0.03 & 0.69 \\
\hline Transportation and communication workers & $2.80 \pm 0.47$ & -0.07 & 0.33 \\
\hline Teachers, athletes, and art performers & $2.96 \pm 0.53$ & 0.06 & 0.35 \\
\hline Healthcare and social workers & $2.86 \pm 0.63$ & -0.04 & 0.68 \\
\hline $\begin{array}{l}\text { Legislators, government administrators, business executives } \\
\text { and managers }\end{array}$ & $2.95 \pm 0.49$ & 0.01 & 0.88 \\
\hline Others (including housekeeper, retirees, and students) & $2.92 \pm 0.55$ & 0.07 & 0.16 \\
\hline \multicolumn{4}{|l|}{ Living arrangement } \\
\hline Living alone & $2.92 \pm 0.65$ & Ref. & Ref. \\
\hline Living with & $2.90 \pm 0.54$ & 0.01 & 0.84 \\
\hline Children $<12$ years & $3.00 \pm 0.48$ & 0.15 & 0.04 \\
\hline Someone who is a student and aged $>=12$ years & $2.88 \pm 0.56$ & 0.03 & 0.64 \\
\hline Elderly people aged $>=65$ & $2.88 \pm 0.53$ & -0.03 & 0.56 \\
\hline \multicolumn{4}{|l|}{ Marital status } \\
\hline Single & $2.98 \pm 0.54$ & 0.10 & 0.02 \\
\hline Married & $2.88 \pm 0.56$ & Ref. & Ref. \\
\hline Others & $2.86 \pm 0.57$ & 0.01 & 0.84 \\
\hline \multicolumn{4}{|l|}{ Area of living } \\
\hline North & $2.86 \pm 0.58$ & Ref. & Ref. \\
\hline Central & $2.94 \pm 0.51$ & 0.09 & 0.02 \\
\hline South & $2.90 \pm 0.55$ & 0.05 & 0.23 \\
\hline East and remote islands & $3.13 \pm 0.47$ & 0.25 & $<0.01$ \\
\hline
\end{tabular}


improve the ability of people to act on information in order to live healthier lives [46].

Recently, a model integrating public health and health care views of general health literacy has been proposed by the European Health Literacy Survey Consortium, which encompasses the 12 matrices concept of health literacy, determinants, and consequences of health literacy [19]. Among the determinants of health literacy proposed by EU, distinction factors include personal, situational, and socio-environmental determinants [19]. This is consistent with our study results indicating that the determinants of AAPHL include education attainment (personal determinants), living arrangement (situational determinants), marital status (situational determinants), and area of living (socio-environmental determinants). As for the personal determinants of the AAPHL score, our study disclosed that lower educational level is a significant influencing factor of AAPHL score, which is similar to those from a previous systematic review for heart failure population [47] and cross-sectional survey of community dwelling older adults [48].

Among the situational determinants, our results demonstrated both living with children below 12 years old and single status were factors significantly associated with higher levels of AAPHL. Previous epidemiological studies strongly suggested that air pollution damages vulnerable children's health and its toxic effects not only occurring at the air-tissue interface of the lung but also affecting on other organs [49]. The government of Taiwan currently implements a health policy in which kindergartens and elementary school should raise colored flag (i.e., which green, yellow, orange, red, purple, and brown respectively) [50] according to the air quality index (AQI) announced by the Taiwan Environmental Protection Administration [51]. This may explain our study result showed a better AAPHL score among participants living with children below 12 years old. As for the other situational determinants of health literacy, our results revealed that participant who were single had better AAPHL scores as compared to those married ones. Individuals living alone were likely to have higher exposures to ambient air pollutants monitoring as they have to go outside often for work or shopping, which in turns may raise their awareness of ambient air pollution [52]. One previous study proposed that single breast cancer survivors would have better generic health literacy and involvement of medical decisions $[52,53]$.

Since AAPHL is a measure related to EHL, certain socio-environmental determinants such as living environment is also a critical factor affecting the awareness of ambient air pollution and health. Our study showed that people living in east and remote islands has higher AAPHL scores than living the other areas. A previous systematic review has mentioned that an association between air quality index and pollution risk perception is existed through the influence of behavior, experience, socioeconomic factors, and information/communication [54]. This might explain our study result because most of the time in Taiwan. According to the Air Quality Monitoring Network of Taiwan Environmental Protection Administration, the air quality is better in the east and remote islands. We speculated the observation that where people from the areas with better air quality tended to have higher awareness of air pollution and health could be related to the frequent self-rescue campaign for ecological conservation and environmental protection against the build-up of petrochemical plants in the neighborhood initiated by local indigenous residents, which might also lead to a success of certain local ambient air pollution control programs and activities.

This study has several limitations. First, due to the cross-sectional study design, causal relationships cannot be established. Second, we cannot rule out potential selection bias because the telephone interview survey would exclude people without home phones or mobile phones. In addition, people who were willing to respond to interview might be different from those who were not, which might have entails at least in some extent certain degrees of selection bias. Although the home phone participants were sampled using PPS method, and a cell phone sample was collected to increase the representativeness of the study sample, low response rates for home phone $(24.90 \%)$ and cell phone (33.5\%) surveys might compromise the truthfulness about some sensitive issues, such as education and occupation. Third, the AAPHL were self-reported in our study, which is subject to information bias. However, some studies have found no differences between self-reported and performancebased health literacy measures [55]. Last, although we have included some socioeconomic status (e.g., occupation, education, living status) as covariates which might influence the level of AAPHL, we did not collect information of medical conditions so that we were unable to further identify certain subgroups (e.g., existing chronic diseases, social support, medical access, etc.) potentially vulnerable to lower level of AAPHL. Additionally, owing to incomplete adjustment for the aforementioned known risk factors for health literacy of ambient air pollution, a potential for residual confounding cannot be entirely excluded. The generalisability of the results may also be limited as our sample was comprised of a larger portion of participants with higher socioeconomic status (i.e., $58 \%$ graduated from college or above) than the general population.

\section{Conclusion}

Adult residents in Taiwan had only moderate level of AAPHL; and education, living arrangement, marital 
status, and area of living were significantly associated with AAPHL. Because ambient air pollution is local and air quality varies seasonally and throughout the day, our study results may provide evidence-based health polity for researchers to consider tailored educational intervention programs with the consideration of personal, situational, and socio-environmental determinants to improve the AAPHL in the community; as well as for practitioners to provide an effective risk communication about air quality with local needs and real-time information across each community.

\begin{abstract}
Abbreviations
AAPHL: Ambient Air Pollution Health Literacy; EHL: Environmental Health Literacy; HLS-EU-Q: European Health Literacy Survey Questionnaire; CVI: Content Validity Index; CFA: Confirmatory Factor Analysis; RMSEA: Root Mean Squared Error of Approximation; SRMR: Standardized Root Mean Square Residual; AGFI: Adjusted Goodness of Fit Index; NFI: Normed Fit Index; NNFI: Non-Normed Fit Index; PPS: Probability Proportional to Size; CATI: Computer-Assisted-Telephone Interview; RDD: Random Digital Dialing SD: Standard Deviation; AQI: Air Quality Index
\end{abstract}

\section{Supplementary Information}

The online version contains supplementary material available at https:/doi. org/10.1186/s12889-021-11658-z.

\section{Additional file 1.}

\section{Acknowledgments}

The authors are grateful for grants from Health Promotion Administration Ministry of Health and Welfare B1090205-109(109-0331-02-18-04) and the Ministry of Science and Technology (grant number MOST-109-0331-02-1804). The funder has no role in conducting and submitting this work. The guarantor is CY Li who takes full responsibility for the work as a whole, including the study design, access to data, and the decision to submit and publish the manuscript.

\begin{abstract}
Authors' contributions
WH Hou, YC Huang, CY Lu, IC Chen, PC Lee, MY Lin, YC Wang, and CY Li designed the study, contributed to the interpretation of results, and drafted the initial manuscript. WH Hou, CY Lu, PC Lee, MY Lin, and CY Li developed the questionnaire and conducted the survey. YC Huang, IC Chen, and CY Lu performed the statistical analyses. WH Hou, PC Lee, Lilis Sulistyorini and CY Li revised the manuscript. All authors reviewed the manuscript. The author(s) read and approved the final manuscript.
\end{abstract}

\section{Funding}

Health Promotion Administration, Ministry of Health and Welfare (B1090205109). The funder has no role in conducting and submitting this work.

\section{Availability of data and materials}

The datasets used and/or analyzed during the current study are available from the corresponding author on reasonable request.

\section{Declarations}

Ethics approval and consent to participate

A telephone consent script that included the following information was concisely described to the study subjects before the telephone interview: purposes of the study, duration of the subject's participation, description of the procedures, description of risks/discomforts, description of benefits, confidentiality, whom (and how) to contact for questions regarding the study (researcher) and their rights as participants, voluntary nature of participation in the research and her/his ability to withdraw without any penalty, and the approximate number of subjects. The informed verbal consent process was considered complete when the study subject raised no more questions and agreed to initiation of the telephone interview. This current study was approved by the National Chung Kung University Governance Framework for Human Research Ethics (No. 109-385) that also approved the content of telephone consent script as well as the procedure for verbal consent used in this study. All authors confirm that all methods were performed in accordance with the relevant guidelines and regulations.

\section{Consent for publication}

Not applicable.

\section{Competing interests}

The authors declare that they have no competing interests.

\section{Author details}

${ }^{1}$ School of Gerontology Health Management \& Master Program in Long-Term Care, College of Nursing, Taipei Medical University, Taipei, Taiwan. ${ }^{2}$ Department of Physical Medicine and Rehabilitation, Department of Geriatric Medicine, \& Department of Education, Taipei Medical University Hospital, Taipei, Taiwan. ${ }^{3}$ Graduate Institute of Clinical Medicine, College of Medicine, Taipei Medical University, Taipei, Taiwan. ${ }^{4}$ Department of Public Health, College of Medicine, National Cheng Kung University, \#1, University Rd, Tainan, Taiwan 701. ${ }^{5}$ Health Promotion Administration, Ministry of Health and Welfare, Taipei, Taiwan. ${ }^{6}$ Department of Health Care Management, National Taipei University of Nursing and Health Sciences, Taipei, Taiwan. ${ }^{7}$ Department of Environmental and Occupational Health, College of Medicine, National Cheng Kung University, Tainan, Taiwan. ${ }^{8}$ Department of Law, College of Social Science, National Cheng Kung University, Tainan, Taiwan. ${ }^{9}$ Department of Environmental Health, Faculty of Public Health, University of Airlangga, Surabaya, Indonesia. ${ }^{10}$ Department of Public Health, College of Public Health, China Medical University, Taichung, Taiwan.

${ }^{11}$ Department of Healthcare Administration, College of Medical and Health Science, Asia University, Taichung, Taiwan.

Received: 19 April 2021 Accepted: 9 August 2021

Published online: 31 August 2021

\section{References}

1. Ambient (outdoor) air pollution [https://www.who.int/news-room/factsheets/detail/ambient-(outdoor)-air-quality-and-health].

2. Ambient and Household Air Pollution and Health: Frequently Asked Questions [https://www.paho.org/en/topics/air-quality-and-health/ambient-a nd-household-air-pollution-and-health-frequently-asked].

3. Cohen AJ, Brauer M, Burnett R, Anderson HR, Frostad J, Estep K, et al. Estimates and 25-year trends of the global burden of disease attributable to ambient air pollution: an analysis of data from the global burden of diseases study. Lancet. 2015;389(10082):1907-18.

4. Burnett R, Chen H, Szyszkowicz M, Fann N, Hubbell B, Pope CA, et al. Global estimates of mortality associated with long-term exposure to outdoor fine particulate matter. Proc Natl Acad Sci. 2018;115(38):9592-7. https://doi.org/1 0.1073/pnas. 1803222115.

5. Braithwaite I, Zhang S, Kirkbride JB, Osborn DPJ, Hayes JF. Air pollution (particulate matter) exposure and associations with depression, anxiety, bipolar, psychosis and suicide risk: a systematic review and Metaanalysis. Environ Health Perspect. 2019;127(12):126002. https://doi.org/1 0.1289/EHP4595.

6. Liu Q, Wang W, Gu X, Deng F, Wang X, Lin H, et al. Association between particulate matter air pollution and risk of depression and suicide: a systematic review and meta-analysis. Environ Sci Pollut Res Int. 2021;28(8): 9029-49. https://doi.org/10.1007/s11356-021-12357-3.

7. Lo WC, Shie RH, Chan CC, Lin HH. Burden of disease attributable to ambient fine particulate matter exposure in Taiwan. J Formosan Med Ass= Taiwan yi zhi. 2017;116(1):32-40. https://doi.org/10.1016/j.ffma.2015.12.007.

8. Das P, Horton R. Pollution, health, and the planet: time for decisive action. Lancet. 2018;391(10119):407-8.

9. Bull KR: The Need for Education in Developing Acceptable Air Pollution Control Strategies. In: Acid rain 2000: Proceedings from the 6th International Conference on Acidic Deposition: Looking back to the past and thinking of the future Tsukuba, Japan, 10-16 December 2000 Volume IIIIIII Conference Statement Plenary and Keynote Papers. edn. Edited by Satake K, Shindo J, Takamatsu T, Nakano T, Aoki S, Fukuyama T, Hatakeyama S, Ikuta K, 
Kawashima M, Kohno Y et al. Dordrecht: Springer Netherlands; 2001 : 1811-1816.

10. Gray KM. From Content Knowledge to Community Change: A Review of Representations of Environmental Health Literacy. Int J Environ Res Public Health. 2018:15(3).

11. Finn $\mathrm{S}, \mathrm{O}$ 'Fallon $\mathrm{L}$. The emergence of environmental health literacy-from its roots to its future potential. Environ Health Perspect. 2017;125(4):495-501. https://doi.org/10.1289/ehp.1409337.

12. Neidell M. Information, avoidance behavior, and health: the effect of ozone on asthma hospitalizations. J Hum Resour. 2009:44(2):450-78.

13. Moretti E, Neidell M. Pollution, health, and avoidance behavior: evidence from the ports of Los Angeles. J Hum Resour. 2011;46(1):154-75.

14. Nutbeam D. The evolving concept of health literacy. Soc Sci Med. 2008; 67(12):2072-8.

15. Hoover AG: Defining Environmental Health Literacy. In: Environmental Health Literacy. edn. Edited by Finn S, O'Fallon LR. Cham: Springer International Publishing; 2019: 3-18.

16. Flinders DJ: Hist Educ Q 1996, 36(1):76-78, Bloom's Taxonomy: A Forty-Year Retrospective, doi: https://doi.org/10.2307/369314.

17. TANKS Emissions Estimation Software, Version 4.09D [https://www3.epa.gov/ ttnchie1/software/tanks/].

18. SPECIATE [https://www.epa.gov/air-emissions-modeling/speciate].

19. Sorensen K, Van den Broucke S, Fullam J, Doyle G, Pelikan J, Slonska Z, et al. Consortium health literacy project $\mathrm{E}$ : health literacy and public health: a systematic review and integration of definitions and models. BMC Public Health. 2012;12(1):80. https://doi.org/10.1186/1471-2458-12-80.

20. Cleary EG, Patton AP, Wu HC, Xie A, Stubblefield J, Mass W, et al. Making air pollution visible: a tool for promoting environmental health literacy. JMIR Public Health Surveill. 2017;3(2):e16. https://doi.org/10.21 96/publichealth.7492.

21. Ramírez AS, Ramondt S, Van Bogart K, Perez-Zuniga R. Public awareness of air pollution and health threats: challenges and opportunities for communication strategies to improve environmental health literacy. J Health Commun. 2019;24(1):75-83. https://doi.org/10.1080/10810730.2019.1 574320 .

22. End of Year 2019$\rangle$ Statistics [https://www.ris.gov.tw/app/en/3910].

23. Sørensen K, Van den Broucke S, Pelikan JM, Fullam J, Doyle G, Slonska Z, et al. Measuring health literacy in populations: illuminating the design and development process of the European health literacy survey questionnaire (HLS-EU-Q). BMC Public Health. 2013;13(1):948. https://doi.org/10.1186/14 71-2458-13-948.

24. Toçi E, Burazeri G, Sørensen K, Kamberi H, Brand H. Concurrent validation of two key health literacy instruments in a south eastern European population. Eur J Pub Health. 2015;25(3):482-6. https://doi.org/10.1093/eurpub/cku190.

25. Consortium H-E: Comparative report of health literacy in eight EU member states. The European Health Literacy Survey (HLS-EU). In.; 2015.

26. Aiken LR. Three coefficients for analyzing the reliability and validity of ratings. Educ Psychol Meas. 1985;45(1):131-42. https://doi.org/10.1177/00131 64485451012.

27. Ginty AT: Construct Validity. In: Encyclopedia of Behavioral Medicine. edn. Edited by Gellman MD, Turner JR. New York, NY: Springer New York; 2013: 487-487.

28. Brown TA. Confirmatory factor analysis for applied research: Guilford publications; 2015.

29. Hu L, Bentler PM. Cutoff criteria for fit indexes in covariance structure analysis: conventional criteria versus new alternatives. Struct Equ Model Multidiscip J. 1999;6(1):1-55. https://doi.org/10.1080/10705519909540118.

30. Baumgartner $\mathrm{H}$, Homburg C. Applications of structural equation modeling in marketing and consumer research: a review. Int J Res Mark. 1996;13(2): 139-61. https://doi.org/10.1016/0167-8116(95)00038-0.

31. Hair JF, Anderson RE, Tatham RL, Black WC: Multivariate data analysis (4th ed.): with readings: Prentice-Hall, Inc.; 1995.

32. Netemeyer RG, Bearden WO, Sharma S. Scaling procedures: issues and applications: sage publications; 2003.

33. Raykov T, Shrout PE. Reliability of scales with general structure: point and interval Estimation using a structural equation modeling approach. Struct Equ Model Multidiscip J. 2002;9(2):195-212. https://doi.org/10.1207/S1532 8007SEM0902 3

34. Li CY, Wu SC, Wen SW. Longest held occupation in a lifetime and risk of disability in activities of daily living. Occup Environ Med. 2000;57(8):550-4. https://doi.org/10.1136/oem.57.8.550.
35. Tang ST, Chang WC, Chen JS, Wang HM, Shen WC, Li CY, et al. Course and predictors of depressive symptoms among family caregivers of terminally ill cancer patients until their death. Psycho-oncology. 2013;22(6):1312-8. https://doi.org/10.1002/pon.3141.

36. Cho YI, Lee SY, Arozullah AM, Crittenden KS. Effects of health literacy on health status and health service utilization amongst the elderly. Soc Sci Med. 2008;66(8):1809-16.

37. van der Heide I, Uiters E, Sørensen K, Röthlin F, Pelikan J, Rademakers J, et al. Health literacy in Europe: the development and validation of health literacy prediction models. Eur J Pub Health. 2016;26(6):906-11. https://doi. org/10.1093/eurpub/ckw078.

38. Cho M, Lee YM, Lim SJ, Lee H. Factors Associated with the Health Literacy on Social Determinants of Health: A Focus on Socioeconomic Position and Work Environment. Int J Environ Res Public Health. 2020:17(18).

39. Harkness JA. Vijver FJRvd, Mohler PP: cross-cultural survey methods. J. Wiley: Hoboken, N.J; 2003.

40. Chiu CT, Chang YH, Chen CC, Ko MC, Li CY. Mobile phone use and health symptoms in children. J Formosan Med Ass= Taiwan yi zhi. 2015;114(7):598604. https://doi.org/10.1016/j.jma.2014.07.002.

41. Al-Kindi SG, Brook RD, Biswal S, Rajagopalan S. Environmental determinants of cardiovascular disease: lessons learned from air pollution. Nat Rev Cardiol. 2020;17(10):656-72. https://doi.org/10.1038/s41569-020-0371-2.

42. Lei X, Chen R, Wang C, Shi J, Zhao Z, Li W, et al. Necessity of personal sampling for exposure assessment on specific constituents of PM2.5: Results of a panel study in Shanghai, China. Environ Int. 2020;141:105786. https:// doi.org/10.1016/..envint.2020.105786.

43. Tong S. Air pollution and disease burden. The Lancet Planetary Health. 2019;3(2):e49-50. https://doi.org/10.1016/S2542-5196(18)30288-2.

44. Hou WH, Huang YJ, Lee Y, Chen CT, Lin GH, Hsieh CL. Validation of the integrated model of health literacy in patients with breast Cancer. Cancer Nurs. 2018;41(6):498-505. https://doi.org/10.1097/NCC.0000000000000540.

45. Pelikan JM, Ganahl K. Measuring health literacy in general populations: primary findings from the HLS-EU Consortium's health literacy assessment effort. Studies in health technology and informatics. 2017;240:34-59.

46. Pleasant A, Maish C, O'Leary C, Carmona RH. A theory-based self-report measure of health literacy: the Calgary charter on health literacy scale. Methodological Innovations. 2018;11(3):2059799118814394.

47. Cajita MI, Cajita TR, Han HR. Health literacy and heart failure: a systematic review. J Cardiovas Nurs. 2015.

48. Chiu HT, Tsai HW, Kuo KN, Leung AYM, Chang YM, Lee PH, Hou WH: Exploring the Influencing Factors of Health Literacy among Older Adults: A Cross-Sectional Survey. Medicina (Kaunas) 2020, 56(7).

49. Kulkarni N, Grigg J. Effect of air pollution on children. Paediatr Child Health. 2008;18(5):238-43. https://doi.org/10.1016/j.paed.2008.02.007.

50. Department of Information and Technology Education MoE, Executive Yuan, Taiwan: Laws and Regulations Database of the Republic of China. 2020.

51. [https://depart.moe.edu.tw/ed2700/Content_List.aspx?n=4519C7E3DC7C6AD0].

52. Crouse DL, Ross NA, Goldberg MS: Double burden of deprivation and high concentrations of ambient air pollution at the neighbourhood scale in Montreal, Canada. Social science \& medicine (1982) 2009, 69(6):971-981.

53. Shen H-N, Lin C-C, Hoffmann T, Tsai C-Y, Hou W-H, Kuo KN. The relationship between health literacy and perceived shared decision making in patients with breast cancer. Patient Education and Counseling. 2018.

54. Cori L, Donzelli G, Gorini F, Bianchi F, Curzio O: Risk Perception of Air Pollution: A Systematic Review Focused on Particulate Matter Exposure. Int J Environ Res Public Health 2020, 17(17).

55. Kiechle ES, Bailey SC, Hedlund LA, Viera AJ, Sheridan SL. Different measures, different outcomes? A systematic review of performance-based versus selfreported measures of health literacy and numeracy. J Gen Intern Med. 2015; 30(10):1538-46. https://doi.org/10.1007/s11606-015-3288-4.

\section{Publisher's Note}

Springer Nature remains neutral with regard to jurisdictional claims in published maps and institutional affiliations. 